\title{
Encounters with physics, chemistry, mathematics and biology at La Universidad de Los Andes: One way to make ours astronomy
}

\section{Orlando A. Naranjo, Patricia Rosenzweig, Orlando B. Escalona, Edgar Guzmán Reinoso, Pablo Bocaranda, Raúl Echeverría and Félix Aguirre}

Departamento de Física, Facultad de Ciencias,

Universidad de los Andes, Mérida 5101, República Bolivariana de Venezuela email: naranjoula@yahoo.com

\begin{abstract}
Encounters with Physics, Chemistry, Mathematics and Biology are carried out at the Universidad de Los Andes (Mérida, Venezuela) since 2000. The main purpose is that the minds of young people get familiarised with science and astronomy, through a well-established relationship linking universities and research centres with schools.
\end{abstract}

Keywords. teaching, outreach, asteroids

\section{Introduction}

In 2000, a group of professors and scientists of the Department of Physics of The University of The Andes (ULA), realised the need that university professors and scientists of research centers should collaborate in improving the education of science and astronomy in the schools, and they give themselves the task of organising an event known as "Encounters with Physics". In 2003, this event was renamed "Encounters with Physics, Chemistry, Mathematics and Biology", due to the incorporation of professors of other departments of the Faculty of Science. One of the most important reasons to create this event was the deep deficiency of knowledge in sciences that is observed in students when they arrive at university, and the lack of interest demonstrated by the young for the study of these disciplines. With the set up of the Encounters one tries to stimulate the use of the laboratories for the education in science, which are very slightly secondhand and/or do not exist in many schools.

\section{Development}

This event has three main components:

(a) The main event which takes place annually during 5 days at the Faculty of Sciences of the ULA, with collaborations among faculty and university students. It is attended by the youngest students and their professors who come from various regions of Venezuela;

(b) Encounters that are developed in each school, organised by their own students, teachers and researchers from ULA;

(c) The Conference for Science Education (Jornadas para la Enseñanza de las Ciencias), which is a traveling exhibit of experiments presented by university students, accompanied by lectures and workshops on science and astronomy that are issued to teachers of the area being visited. 
So far some 60,000 students attended and more than 1,000 professors and teachers have attended the lectures and workshops taught by researchers from ULA. With this event we want to make alliances with other nations to promote a better union between staff from universities and the improvement in science and astronomy teaching in schools, making a contribution to make it more interesting to youngsters and the general public.

\section{Asteroids for popularisation of astronomy and technology}

We have been proposing to use the naming of asteroids as a tool for the popularisation of astronomy, science and technology. This tool has been used by organisers of educative activities in schools and museum as a price to the winners of scientific and technological events which they promote. Actually, there are two events, one in Venezuela and one in Brazil, which has used this proposal as an attractive alternative for popularisation. The first event was called Bautizo Espacial (Space Baptism) and was a contest of scientific stories written by medium(fundamental)- and high school students. This event was organised by universities, the amateur astronomy association (ALDA) and governmental institutions. It was carried out in the Venezuelan State of Lara. The second event, called Grande Desafío (Big Challenge), was a competition where teams (with 3 to 6 medium(fundamental)- and high school students) were challenged to build a prototype of an equipment to fight forest fire. This happening was organised by the Exploratory Science Museum of the State University of Campinas in Brazil (Museu Explóratorio de Ciências, UNICAMP). Both events had national publicity in newspapers, radios, TV and web pages, reaching a massive amount of people in both countries. In both events parallel activities were carried out promoting public knowledge of astronomy. The asteroids that have been named (and other proposed to be named) were discovered in a search program developed by the Group of Theoretical Astrophysics of the University of the Andes in Mérida (Grupo de Astrofísica Teórica, Universidad de Los Andes). The observations were done at Llano del Hato National observatory, located in Mérida State. Asteroids for Popularisation of Astronomy may be held in any country interested, during the celebration of the International Year of Astronomy in 2009 and beyond.

\section{Public understanding of science and astronomy and its popularisation to all levels of society}

Universities and research centers have established a relation with schools, and the general public, in the zeal to provide the lastest scientific news to them and to interest the young students in particular to study the various sciences. With this project, the Universidad de Los Andes is contributing in the public understanding of science and its popularisation to all levels of society.

\section{References}

Mercado, A. \& Michelena H. 2005, Ciencia y Tecnología en América Látina. Una mirada desde Venezuela (Caracas: Universidad Central de Venezuela - Fundación Polar)

Roche, M. 1996, Perfil de la Ciencia en Venezuela (Caracas: Ediciones de la Fundación Polar) Rosenzweig, P. 2004, Revista del Consejo de Desarrollo Científico, Humanístico y Tecnológico CDCHT, 10, 56 http://www.saber.ula.ve/handle/123456789/21354

Rosenzweig, P. \& Escalona O. 2001, Revista del Consejo de Desarrollo Científico, Humanístico y Tecnológico - CDCHT, 5, 34 http://www.saber.ula.ve/handle/123456789/21139

Villarroel, C. 2005, Sistema de evaluación y acreditación de las universidades venezolanas: origen, concepción e instrumentación (Caracas: IESALC/UNESCO) 